\title{
Mechanical and Structural Properties of Fluorine-Ion-Implanted Boron Suboxide
}

\author{
Ronald Machaka, ${ }^{1,2}$ Bonex W. Mwakikunga, ${ }^{3,4}$ Elayaperumal Manikandan,, 5 \\ Trevor E. Derry, ${ }^{1,6}$ Iakovos Sigalas, $^{1,2}$ and Mathias Herrmann ${ }^{7}$
}

\author{
${ }^{1}$ DST/NRF Centre of Excellence in Strong Materials, University of the Witwatersrand, Private Bag 3, Wits, \\ Johannesburg 2050, South Africa \\ ${ }^{2}$ School of Chemical and Metallurgical Engineering, University of the Witwatersrand, Private Bag 3, Wits, \\ Johannesburg 2050, South Africa \\ ${ }^{3}$ National Centre for Nano-Structured Materials, CSIR, P.O. Box 395, Pretoria 0001, South Africa \\ ${ }^{4}$ Department of Physics and Biochemical Sciences, University of Malawi, The Polytechnic, Private Bag 303, Chichiri, \\ Blantyre 0003, Malawi \\ ${ }^{5}$ Nano Centre, Polymer Nanotechnology Center \& Department of Physics, B. S. Abdur Rahman University, \\ Vandalur, Chennai-600048, India \\ ${ }^{6}$ School of Physics, University of the Witwatersrand, Private Bag 3, Wits, Johannesburg 2050, South Africa \\ ${ }^{7}$ Fraunhofer Institute for Ceramic Technologies and Systems, Winterbergstraße 28, 01277 Dresden, Germany
}

Correspondence should be addressed to Ronald Machaka, ronald.machaka@wits.ac.za

Received 30 April 2011; Revised 18 September 2011; Accepted 19 September 2011

Academic Editor: W. Ensinger

Copyright ( $) 2012$ Ronald Machaka et al. This is an open access article distributed under the Creative Commons Attribution License, which permits unrestricted use, distribution, and reproduction in any medium, provided the original work is properly cited.

\begin{abstract}
Results on a systematic study on the effects of ion implantation on the near-surface mechanical and structural properties of boron suboxide $\left(\mathrm{B}_{6} \mathrm{O}\right)$ prepared by uniaxial hot pressing are reviewed. $150 \mathrm{keV}$ fluorine ions at fluences of up to $5.0 \times 10^{16}$ ions $/ \mathrm{cm}^{2}$ were implanted into the ultrahard ceramic material at room temperature and characterized using Raman spectroscopy, atomic force microscopy, and scanning electron microscopy with energy-dispersive X-ray spectroscopy. Evidence of ion-beam-assisted nucleation of novel clustered $\mathrm{B}_{x} \mathrm{O}_{y} \mathrm{~F}_{z}$ particles by ion implantation is revealed. In addition, obtained results also reveal that fluorine implantation into the $\mathrm{B}_{6} \mathrm{O}$ specimen leads to an overall degradation of near-surface mechanical properties with increasing fluorine fluence. Implications of these observations in the creation of amorphous near-surface layers by high-dose ion implantation are discussed in this paper.
\end{abstract}

\section{Introduction}

Energetic ions have been of interest to researchers for their capability of (i) characterization of materials, (ii) modification of materials, and more recently (iii) synthesis of new materials. Of particular interest is the possibility of ion beams to circumvent thermodynamic limits related to conventional methods such as diffusion, solubility, deposition, and alloy formation by providing high kinetic energy through ion impact and utilizing ballistic effects during ionsolid interaction [1-4]. Moreover, ion implantation allows the precise control of the ion energy, ion fluence, dopant distribution as well as a choice of the ion species. As a result the surface modification conditions can also be influenced with a great deal of reproducibility and control for specific needs, that is, either synthesis, modification, or characterization of materials.

The increasing fascination with low-dimensional material structures is mainly motivated by the search for new materials with tunable novel properties of evident technological relevance. It is therefore not surprising that nanostructured materials are gaining growing importance due to their unique properties that are intermediate between those corresponding to the bulk solids and molecules. In recent years many groups have reported on the ion-beam-assisted 
synthesis of novel nanostructured materials by ion implantation $[3,5-7]$. In addition, unique and sometimes superior mechanical $[1,8]$, structural $[2,9-11]$, optoelectronic $[7$, 12], corrosion, and tribomechanical surface properties [2, 13] of the ion-implanted materials have also been reported.

Boron suboxide, $\mathrm{B}_{6} \mathrm{O}$, is an superhard boron-rich ceramic material. It exhibits a rather unusual and wide range of superior properties; among these are high hardness with low density, high mechanical strength, oxidation resistance up to high temperatures as well as its chemical inertness [14-18]. The potential applications of $\mathrm{B}_{6} \mathrm{O}$ as ideal wearreduction coatings for high-speed cutting tools, abrasives, or other high-wear applications, for example, have been an object of intense interest in recent years $[19,20]$. However, despite the intensive research efforts, the commercial applications are yet to be realized. This is partly because of the low fracture toughness of hot-pressed materials [17, 18] and the considerable practical challenges associated with the densifying stoichiometric $\mathrm{B}_{6} \mathrm{O}$ material with good crystallinity $[17,18]$. Furthermore, numerous mechanical properties of the material were until recently rather poorly understood $[14,21]$.

Preliminary first-principle ab initio density functional calculations of the structural properties of boron suboxide (nominally $\mathrm{B}_{6} \mathrm{O}$ ) by Lowther suggest that the strength of the bonding in $\mathrm{B}_{6} \mathrm{O}$ (and other boron-rich superhard materials such as $\mathrm{B}_{4} \mathrm{C}$ and $\left.\mathrm{AlMgB}_{14}\right)$ may be enhanced by the presence of a high electronegativity interstitial in the structure [22]. The computational calculations confirm the shortening of covalent bonds which is believed to favour higher elastic constants and hardness values. By introducing energetic fluorine ions into $\mathrm{B}_{6} \mathrm{O}$ using ion implantation- $\mathrm{a}$ nonequilibrium technique of choice for introducing "controlled" defects into the near-surface layers $[4,23]$. To the best of our knowledge, no work has been reported on effect of ion implantation on the near-surface mechanical and structural properties of $\mathrm{B}_{6} \mathrm{O}$.

In our work, the radiation effects of the ceramic material under heavy ion irradiation have been studied to develop an understanding of the radiation resistance evolution with respect to the material properties. We apply nanoindentation, Raman spectroscopy, atomic force microscopy (AFM), and scanning electron microscopy (SEM) with energy-dispersive $\mathrm{X}$-ray spectroscopy (EDX) to demonstrate the synthesis of $\mathrm{B}_{x} \mathrm{O}_{y} \mathrm{~F}_{z}$ clustered particles using $150 \mathrm{keV}$ fluorine ion implantation into $\mathrm{B}_{6} \mathrm{O}$. This paper reviews results obtained in the study.

\section{Experimental Methods}

$\mathrm{B}_{6} \mathrm{O}$ powder synthesized at the Fraunhofer Institute for Ceramic Technologies and Systems, Dresden, Germany, by reacting $\mathrm{B}$ and $\mathrm{B}_{2} \mathrm{O}_{3}$ as detailed by Andrews et al. in [18] was prepared and uniaxially hot-pressed in $h \mathrm{BN}$ pots under argon environment at $1800^{\circ} \mathrm{C}$ and $50 \mathrm{MPa}$ for $20 \mathrm{~min}$ at the School of Chemical and Metallurgical Engineering, University of the Witwatersrand, Johannesburg, South Africa. The hot-pressed compacts were then prepared using a method
TABLE 1: The nomenclature of the unimplanted and implanted samples.

\begin{tabular}{lccc}
\hline Sample no. & Ion species & $\begin{array}{c}\text { Energy } \\
\mathrm{keV}\end{array}$ & $\begin{array}{c}\text { Fluence } \\
\mathrm{F}^{+} / \mathrm{cm}^{2}\end{array}$ \\
\hline $\mathrm{A}$ & - & - & - \\
$\mathrm{B}$ & $\mathrm{F}^{+}$ & 150 & $1.0 \times 10^{14}$ \\
$\mathrm{C}$ & $\mathrm{F}^{+}$ & 150 & $5.0 \times 10^{14}$ \\
$\mathrm{D}$ & $\mathrm{F}^{+}$ & 150 & $5.0 \times 10^{15}$ \\
$\mathrm{E}$ & $\mathrm{F}^{+}$ & 150 & $1.0 \times 10^{16}$ \\
$\mathrm{~F}$ & $\mathrm{~F}^{+}$ & 150 & $3.0 \times 10^{16}$ \\
$\mathrm{G}$ & $\mathrm{F}^{+}$ & 150 & $5.0 \times 10^{16}$ \\
\hline
\end{tabular}

prescribed by Machaka et al. in [21]. The density of the hotpressed compacts measured $2.44 \mathrm{~g} / \mathrm{cm}^{3}$.

$150 \mathrm{keV}$ fluorine ions were implanted into hot-pressed $\mathrm{B}_{6} \mathrm{O}$ specimen at fluences between $1.0 \times 10^{14}$ to $5.0 \times$ $10^{16}$ ions $/ \mathrm{cm}^{2}$ at room temperature. A modified VarianExtrion 200-20A2F model ion implanter at iThemba LABS (Gauteng), Johannesburg was used. The nomenclature of the unimplanted and implanted samples is tabulated in Table 1. The depth distribution of the radiation damage and implanted ion profile were estimated using SRIM2010 [24], a suite of Monte Carlo computational codes popular for the simulation of the interactions of energetic ions with the target material.

The specimen's surface microstructure and composition were characterized by SEM and EDX, respectively. The specimen surface topography was characterized using AFM. Gwyddion v2.24 [25], a modular multiplatform software for profilometric data analysis, was used to analyze AFM images. The powder diffraction patterns were collected using a $\mathrm{Cu}$ $\mathrm{K}_{\alpha}$ source in the Bragg-Brentano backscattering geometry over a $10^{\circ}-90^{\circ} 2 \theta$ range, with a $0.02^{\circ}$ step size. Raman measurements performed at the CSIR's National Centre for nanostructured materials nanomaterial characterization facility under ambient conditions using a $514.5 \mathrm{~nm} \mathrm{Ar}^{+}$ion excitation were used to characterize the ion beam induced structural modifications whilst the mechanical properties of the unimplanted and implanted samples were determined using nanoindentation at Nelson Mandela Metropolitan University, Port Elizabeth. Details of the experimental procedures of the Raman spectroscopy and the nanoindentation measurements are also reported elsewhere $[14,26]$.

\section{Results and Discussions}

\subsection{Structural Characterization}

3.1.1. Implant Depth Profile. The distribution of the implanted fluorine ions estimated using SRIM2010 can be described as a near-Gaussian shape function characterized with a projected range of about $450 \mathrm{~nm}$ and an estimated range straggling of about $60 \mathrm{~nm}$. However, in practice we are aware that the SRIM estimation does not take into account the possible surface sputtering, dynamic annealing, and diffusion processes taking place during ion implantation. 


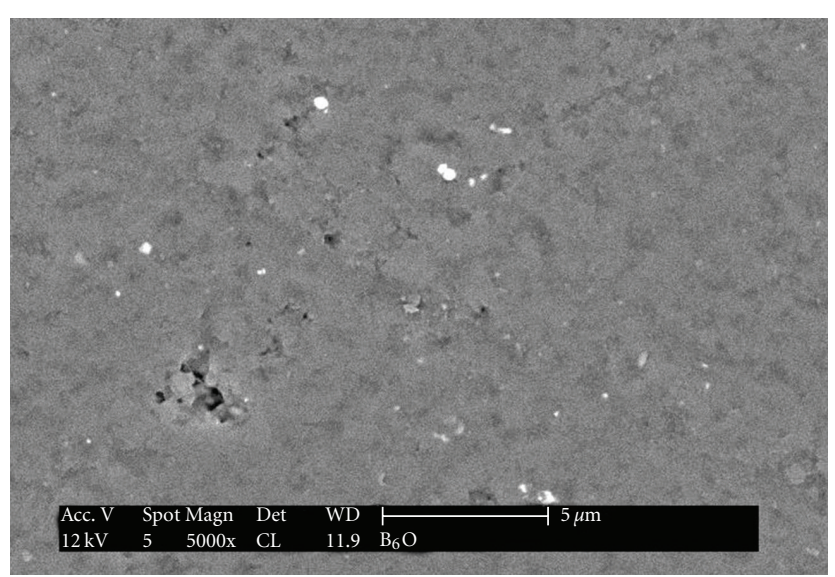

(a)

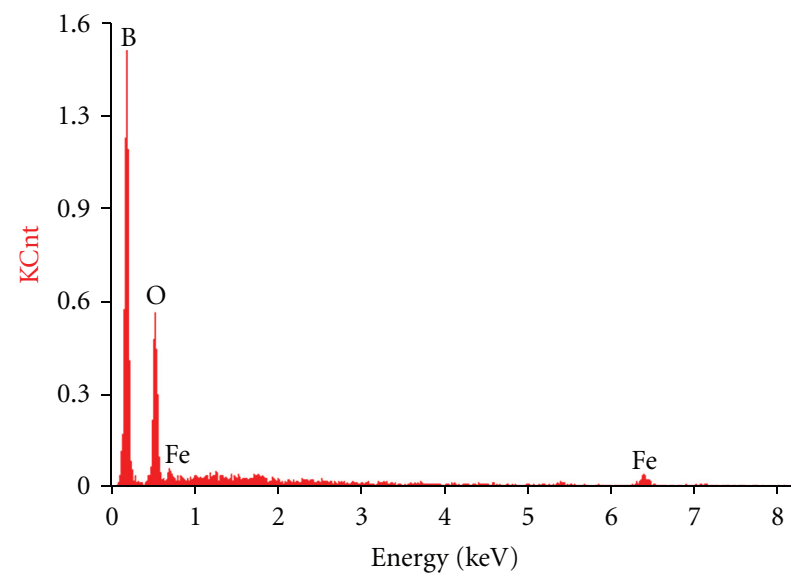

(b)

FIgURE 1: It shows the SEM surface micrograph (a) and the EDX surface compositional analysis (b) of the hot-pressed $\mathrm{B}_{6} \mathrm{O}$ specimen. Iron contamination (bright spots on SEM micrograph) is responsible for EDX elemental peaks observed.

3.1.2. SEM and EDX Analysis. The surface morphology and compositional analysis of unimplanted $\mathrm{B}_{6} \mathrm{O}$ specimen as determined by SEM and EDX are shown in Figures 1(a) and 1(b), respectively. By and large, the SEM micrograph shows a homogeneous $\mathrm{B}_{6} \mathrm{O}$ microstructure with visible pores on the specimen surface as a direct result of some considerable practical challenges in the densification of $\mathrm{B}_{6} \mathrm{O}$ by hot pressing [15-17].

The analysis of the surface composition by EDX is also indicative of nominally pure $\mathrm{B}_{6} \mathrm{O}$ phase. The observed iron contamination (typically a few wt.\%) is expected and unavoidable possibly as a direct consequence of the abrasion of the steel ball and the containment cell during powder ball milling [19, 20, 27].

The SEM and EDX analysis of the heavily implanted specimen (B4 in Figures 2(b)-2(d)), for example, shows obvious dissimilarities between the unimplanted and the implanted specimen. Firstly, in addition to the homogeneous $\mathrm{B}_{6} \mathrm{O}$ phase the surface pores and the iron and chromium contamination, SEM micrographs show evidence of the existence of additional clusters of ion-beam-synthesized particles. Secondly, image analysis of the microstructure (Figures 2(b) and 2(c)) indicates that the average particle sizes of the formed clusters is $110 \mathrm{~nm}$. Thirdly, the measured EDX pattern shows two weak iron peaks at $0.75 \mathrm{ev}$ and $6.4 \mathrm{eV}$. Although the positions of the $0.75 \mathrm{eV}$ iron peak and the fluorine peak coincide, there appears to exist enough evidence observed to indicate a $\mathrm{B}_{x} \mathrm{O}_{y} \mathrm{~F}_{z}$ stoichiometry for the ion-beam-synthesized clustered particles. We have also observed that the compositional change becomes more significant with increasing fluorine implantation dose. The $\mathrm{B}_{6} \mathrm{O}$ signature EDX pattern unimplanted specimen is depicted in Figure 1(b) [15, 28].

3.1.3. Raman Spectroscopy Analysis. Raman scattering spectroscopy is very sensitive to the nature of crystalline structure, disorder, and amorphization and is often employed to characterize ion-implantation-induced defects and any irregularity in the crystalline symmetry. The rather popular technique offers a rapid, nondestructive, and simple diagnostic probe for the evaluation of the structural modifications imposed by ion implantation and for optical characterization of ion-implanted specimens since the penetration depth of the laser beam is often of the order of the depth of penetration of implanted ions.

Figures 3 and 4 show the Raman spectra of pristine (specimen $\mathrm{A}$ ) and $\mathrm{F}^{+}$-implanted hot-pressed $\mathrm{B}_{6} \mathrm{O}$ (specimens $B$ to $G$ ). The Raman spectrum of the pristine specimen is characteristic of nominal composition $\mathrm{B}_{6} \mathrm{O}$ [21, 29-32].

The measured Raman spectra are evidently characterized by a relatively low Raman signal to noise ratio. Nevertheless, it is not difficult to see that $\mathrm{F}^{+}$implantation at fluences up to $5.0 \times 10^{15}$ ions $/ \mathrm{cm}^{2}$ reveals that the material resists amorphization and retains the crystal structure of $\mathrm{B}_{6} \mathrm{O}$. At the same time, implantation at fluences above $5.0 \times 10^{15}$ ions $/ \mathrm{cm}^{2}$ clearly shows that the signature Raman spectrum of $\mathrm{B}_{6} \mathrm{O}$ predominately disappears (specimen D).

Rao et al. [33, 34], in Raman scattering spectroscopy, the main effect in going from the crystalline to amorphous form is the introduction of characteristic features in the frequencies and line shapes of the Raman modes. However, for a diatomic lattice, the effect of amorphization should be a decrease in intensity of the lattice modes and even the disappearance of these modes at higher ion implantation doses. Accordingly, we tentatively attribute the disappearance of the signature $\mathrm{B}_{6} \mathrm{O}$ Raman spectrum at implantation fluences exceeding $5.0 \times 10^{15}$ ions $/ \mathrm{cm}^{2}$ to amorphization as a result of ion-induced radiation damage.

Measured spectra on samples implanted at fluences beyond $5.0 \times 10^{15}$ ions $/ \mathrm{cm}^{2}$ reveal an almost unrelated and new asymmetrically broadened Raman feature centred around $1550 \mathrm{~cm}^{-1}$. In general, it is widely accepted in the field that the observed line shape asymmetry is consistent with the size-dependent effects in measured Raman modesoptical phonon confinement [35]. The existence of ionbeam-synthesized aggregates made up of micro- and/or nanosized particles is known to exhibit this phenomenon. For example, we recently reported on the Raman spectra of $c \mathrm{BN}$ nanocrystals formed by $\mathrm{He}^{+}$ion implantation into 


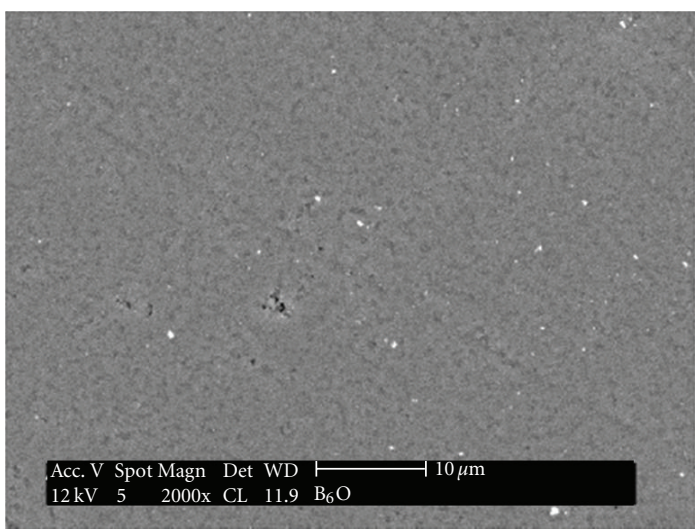

(a)

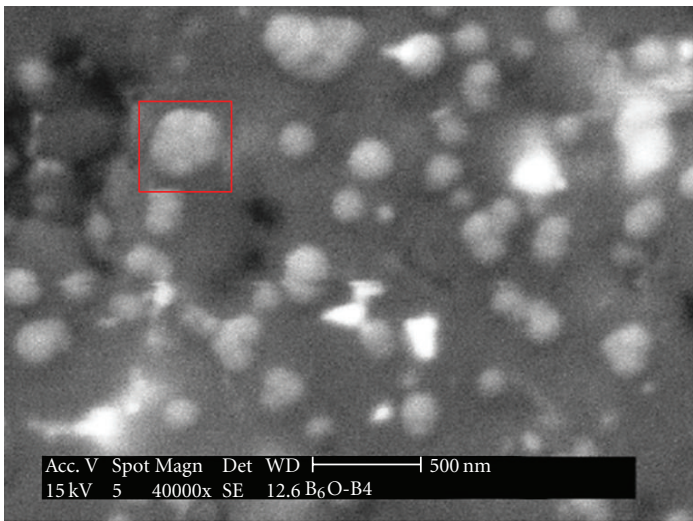

(c)

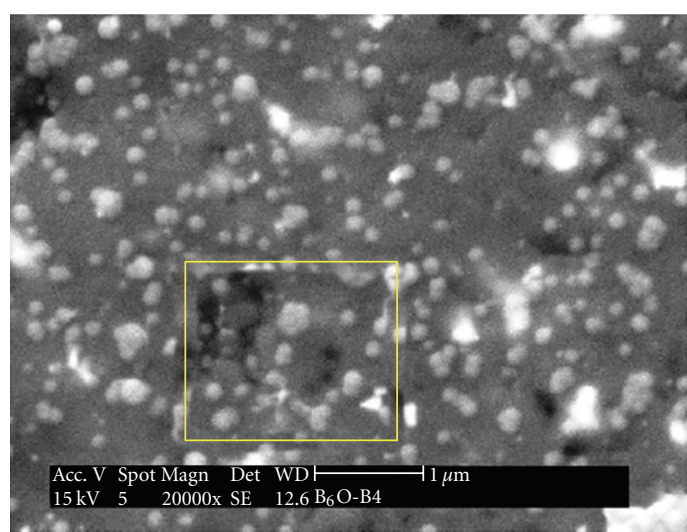

(b)

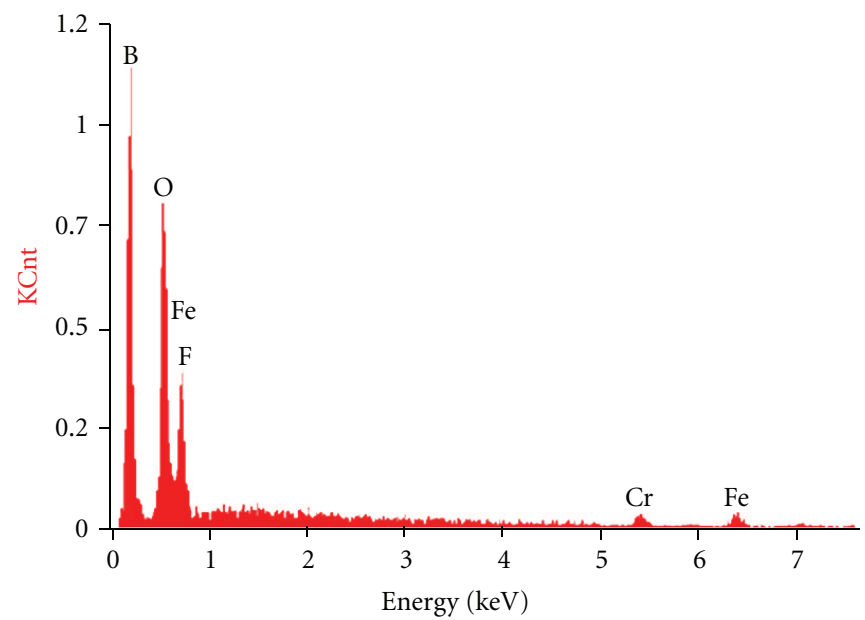

(d)

Figure 2: A depiction of SEM images measured on the surface of (a) an unimplanted $\mathrm{B}_{6} \mathrm{O}$ specimen, ((b) and (c)) a $5.0 \times 10^{15} \mathrm{~F}^{+}$ions/ $\mathrm{cm}^{2}$ implanted $\mathrm{B}_{6} \mathrm{O}$ specimen showing clusters of particles embedded in the samples synthesized by fluorine-ion-beam implantation, and (d) an EDX measured pattern on one such ion-beam-synthesized cluster which is highlighted in micrograph (c).

$h \mathrm{BN}[9]$. Several other researchers have also reported on the ion-beam synthesis of other nanostructures phased by ion bombardment $[3,5,6]$. In fact, ion implantation is a method of choice for synthesizing nc-Si in optoelectronics [7].

A further increase in the implantation fluence beyond $5.0 \times 10^{15}$ ions $/ \mathrm{cm}^{2}$ gives rise to further increase in both width and intensity of the asymmetrically broadened Raman feature. Furthermore, increases in the feature's peak intensity with increasing ion dose may be a result of the increase in volume fraction of the clustered particles in the material surface layer. A critical fluence of about $3.0 \times 10^{16}$ ions $/ \mathrm{cm}^{2}$ was observed beyond which the volume fraction of the clustered particles will reduce owing to the existence of surface sputtering and possibly radiation damage.

In summary, a possible explanation of this Raman scattering characteristic in ion-implanted $\mathrm{B}_{6} \mathrm{O}$ could be the nucleation of a new micro- or nanocrystalline phase in the $\mathrm{B}_{6} \mathrm{O}$ matrix. At higher doses, ion implantation creates a nonequilibrium solid-state supersaturation of the implanted ions in solutions which could induce the precipitation of ionbeam-synthesized nanostructured particle nuclei effectively, due to thermodynamic stabilization. These nuclei grow additionally as a result of the surface deposition of solvated ions. According to Shen et al. [8], the ion beam synthesis of the nanostructured particles could be conceptualized into several steps: (i) stopping and accumulation of $\mathrm{F}$ implants in the near-surface area of the host $\mathrm{B}_{6} \mathrm{O}$ matrix, (ii) supersaturation of this area by $\mathrm{F}$ implants, (iii) formation of nuclei of a $\mathrm{B}_{x} \mathrm{O}_{y} \mathrm{~F}_{z}$ phase, and (iv) growth of the nanoparticles from the nuclei. Stepanov in reference [3] best illustrates the basic physical processes involved in the formation of nanoparticles from an implant with respect to the ion dose in Figure 5 shown below.

3.2. Mechanical Characterization. The representative indentation load-displacement $(P-h)$ curves continuously measured during loading and unloading for the four specimens under investigation (unimplanted (specimen A) and fluorine implanted (specimens C, D, and G)) are shown in Figure 6. The intrinsic hardness $H(E)$ and the elastic modulus $E$ of specimen were evaluated from the nanoindentation response curves by applying a modified O\&P procedure as outlined in 


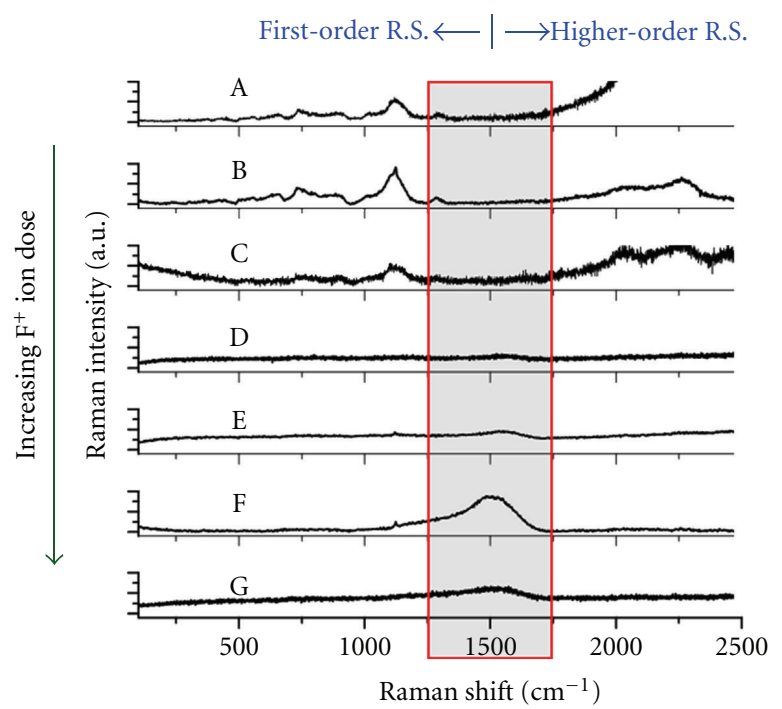

Figure 3: The Raman spectra of unimplanted (specimen A) and fluorine-ion-implanted (specimens $\mathrm{B}$ to $\mathrm{G}$ ) $\mathrm{B}_{6} \mathrm{O}$ specimen. The spectra are shifted along the $y$-axis for better comparison. The $y$ axis is normalized.

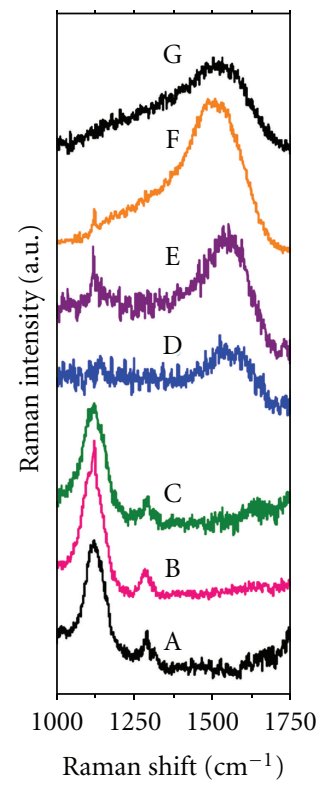

FIGURE 4: An expanded view of the normalized Raman spectra of the $1550 \mathrm{~cm}^{-1}$ mode. A comparison between measured (dotted curve) and calculated first-order Raman line shapes of ionimplanted $\mathrm{B}_{6} \mathrm{O}$. Again, the $y$-axis is normalized, and the spectra are shifted along the $y$-axis for better comparison.

Appendix A [37-39]. The AFM imaging of the indentation impressions and analysis has been relegated to Appendix B. An average surface roughness (determined from the AFM images, see Figure 9) of about $7 \mathrm{~nm} R_{a}$ measured on the surface appears to be a very small fraction of the maximum indentation depth and does not appear to influence the mechanical properties significantly. Table 2 shows a summary of the calculated values of $H(E)$ and $E$, as well as the

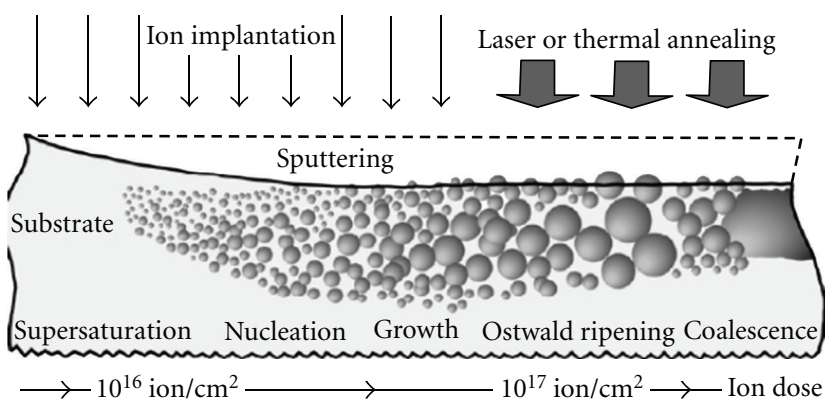

FIGURE 5: An illustration of the basic physical processes (from left to right) involved in the formation of clustered particles from an implant with respect to the ion dose. Surface sputtering under irradiation is also considered [36]. Diagram courtesy of Stepanov [3]. Note. In this study, all characterization was done on asimplanted specimen; no annealing was done.

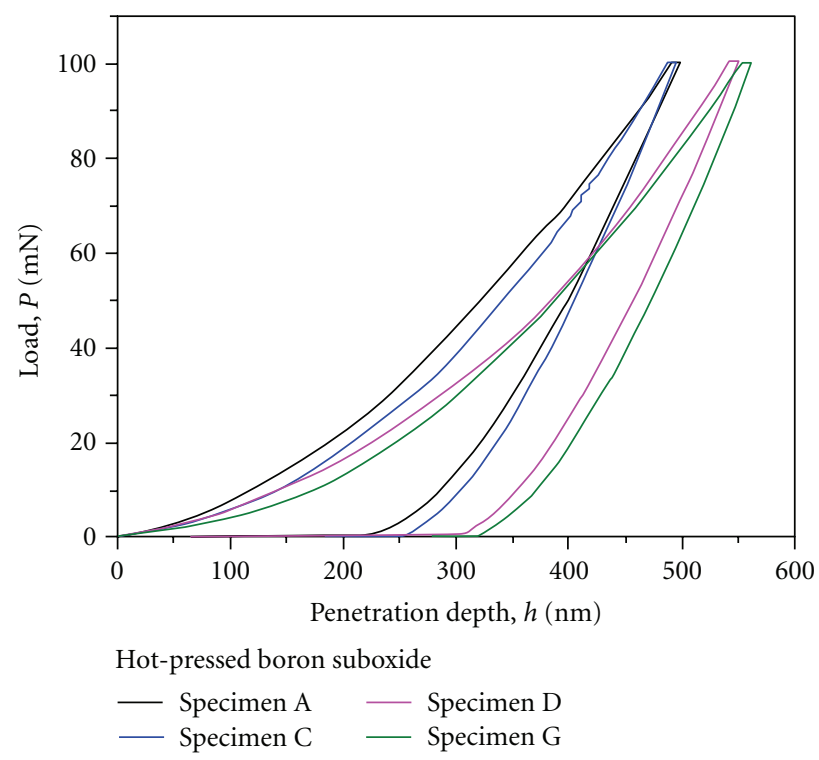

FIGURE 6: Representative indentation response curves measured during the nanoindentation measurements on the unimplanted (specimen A), and fluorine-implanted (specimen C, D, and G) hotpressed boron suboxide specimen.

TABle 2: A summary of the effect of ion implantation on $H(E), E$, the ratio $H / E$, and the Meyer's index $n$.

\begin{tabular}{lcccc}
\hline Specimen & $\begin{array}{c}H(E) \\
\mathrm{GPa}\end{array}$ & $\begin{array}{c}E \\
\mathrm{GPa}\end{array}$ & $H / E$ & $n$ \\
\hline $\mathrm{A}$ & 31.0 & 328.0 & 0.093 & 1.66 \\
$\mathrm{C}$ & 29.0 & 359.0 & 0.082 & 1.92 \\
$\mathrm{D}$ & 23.0 & 300.0 & 0.076 & 1.94 \\
$\mathrm{G}$ & 21.0 & 292.0 & 0.073 & 1.96 \\
\hline
\end{tabular}

ratio $H / E$ and the Meyer's index, $n$ (see (1) below), also calculated from the experimentally measured loading $P-h$ curves.

In order to exhibit all dependences (of the mechanical properties on the fluence of implantation) in one figure for 


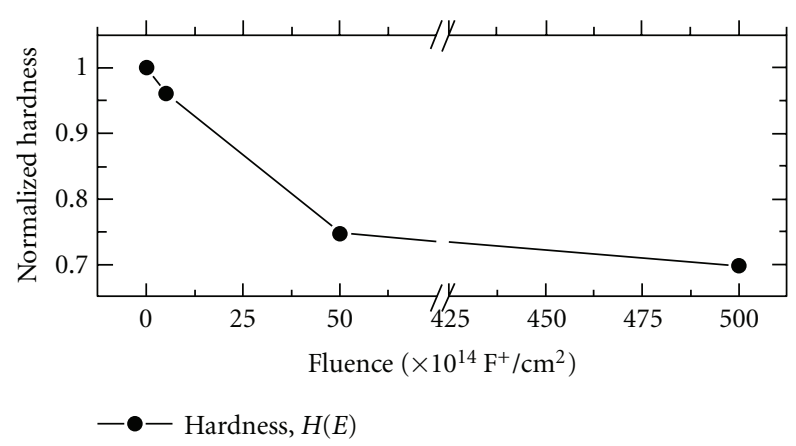

(a) Intrinsic hardness

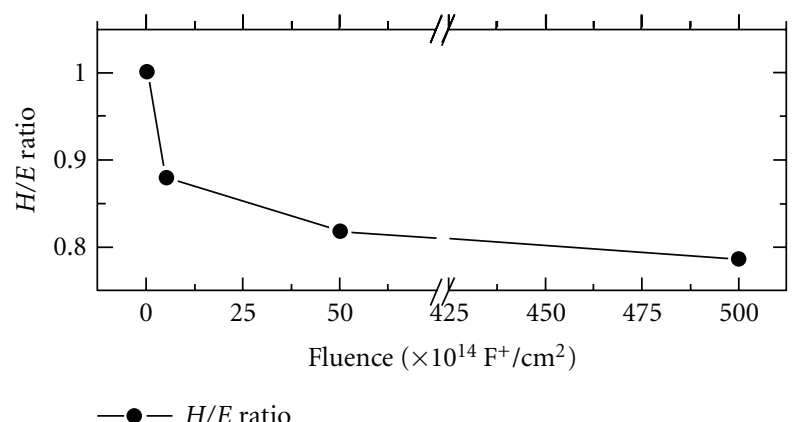

(c) $H / E$ ratio

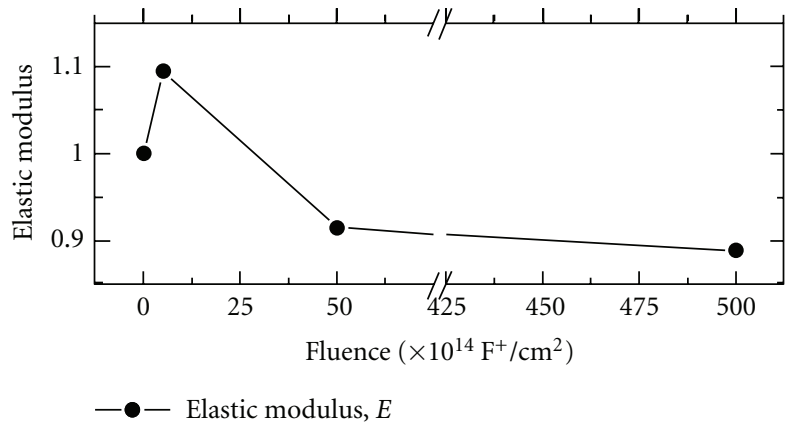

(b) Elastic modulus

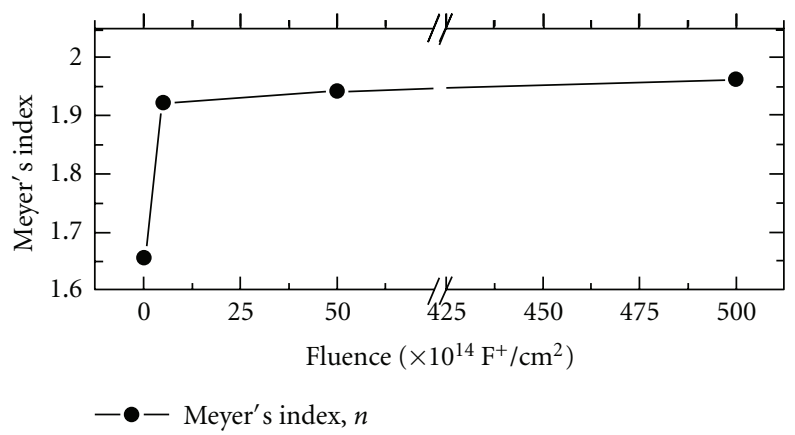

(d) The Meyer's index measured for hot-pressed $\mathrm{B}_{6} \mathrm{O}$ samples irradiated with various fluences of $\mathrm{F}$ ions

Figure 7

ease of analysis and comparison, the calculated values were normalized to those measured for the control specimen A and presented in Figure 7.

The characterized mechanical properties are evidently influenced by the fluence of implantation. For example, an increase in the fluorine ion dose is observed to result in an overall decrease in the intrinsic hardness and the elastic modulus of the material, a decrease in the values of the ratio $H / E$, and a general increase in the Meyer's index values. These trends reflect the changes in the structure or the material, the mechanism of plastic deformation of the irradiated material, and most probably, after ion-implantation-induced amorphization of the pristine structure, as further discussed below.

3.2.1. Intrinsic Hardness. From the measured $P$ - $h$ curves, the intrinsic hardness of the control pristine $\mathrm{B}_{6} \mathrm{O}$ specimen was evaluated to be $31 \pm 0.2 \mathrm{GPa}$, a value in close agreement with recently published microhardness $[15,16]$ and nanohardness [40] values. The effect of F-ion implantation on the hardness value $H(E)$ is summarized in Figure 7(a). The change in the hardness value is quite small for implantation doses of up to $5 \times 10^{14} \mathrm{~F}^{+} / \mathrm{cm}^{2}$, while a severe decrease of about $30 \%$ is observed for a dose of $5 \times 10^{16} \mathrm{~F}^{+} / \mathrm{cm}^{2}$.

Two mechanisms of plastic deformation, namely, phase transformation and plastic flow, can be responsible for a change in hardness during a nanomechanical testing experiment. The main indicator for the operation of phase transformation during the nanoindentation experiment is the appearance of dislocation discontinuities (kinks or pop-ins) in the $P$ - $h$ curves $[41,42]$. Their absence in the $P$ - $h$ curves of hot-pressed $\mathrm{B}_{6} \mathrm{O}$ presented here (see Figure 6) suggests that the testing performed in the present study does not induce significant phase transformation; we suspect that the plastic deformation of hot-pressed $\mathrm{B}_{6} \mathrm{O}$ is accomplished by plastic flow. We consider the plastic flow to be associated with structural changes caused by radiation damage and the subsequent fluorine irradiation-induced amorphization. This relation supports the suggestion of plastic flow as the deformation mechanism of the ion-implanted hot-pressed ceramic $\mathrm{B}_{6} \mathrm{O}$ material. The softening of the ion-implanted specimen can be attributed to the amorphization of the surface layer, as identified by the micro-Raman spectroscopy characterization results.

3.2.2. Elastic Modulus. From the measured $P$ - $h$ curves, the elastic modulus of the pristine $\mathrm{B}_{6} \mathrm{O}$ specimen was evaluated to be $330 \pm 4 \mathrm{GPa}$, a value also consistent with previously published data [15].

The Young's modulus is clearly correlated with the amorphization of the crystalline structure, although for low-irradiation fluences the values increase by about $10 \%$ before rapidly decreasing as amorphization of the crystalline structure supposedly takes place. We propose that the effect of ion implantation on the elastic modulus is related to the induced decrease in the short-range order (distortion) of the $\mathrm{B}_{12}$ icosahedral network. The initial increase might be attributed to the increase of the concentration of the interstitial nitrogen ions in the implanted surface region. A lower elastic modulus of the implanted hot-pressed $\mathrm{B}_{6} \mathrm{O}$ 
TABLE 3: $H / E$ ratios of $\mathrm{B}_{6} \mathrm{O}$ and hard ceramic materials.

\begin{tabular}{lc}
\hline Material & $H / E$ ratio \\
\hline Diamond & $0.09-0.1[44]$ \\
Hot-pressed $\mathbf{B}_{6} \mathbf{O}$ & $\mathbf{0 . 0 9 3}$ \\
$\mathrm{B}_{4} \mathrm{C}$ & $0.07-0.09[44]$ \\
$\mathrm{SiC}$ & $0.080[44]$ \\
$\mathrm{Si}_{3} \mathrm{~N}_{4}$ & $0.080[44]$ \\
Silicon & $0.062[46]$ \\
\hline
\end{tabular}

could be associated with the implantation-induced increase in the B-B bond angle deviations or simply the collective distortion of the individual $B_{12}$ icosahedra or/and the $\alpha$ rhombohedral framework, as a result of ion bombardment (see Figure 7(b)); it is well accepted that material having crystalline phases has a higher modulus than the materials with amorphous structure [43]. This is an observation which correlates well with the measured Raman results discussed in this paper (Figure 3).

3.2.3. $H / E$ Ratio. The ratio of $H(E)$ to $E,(H / E)$ is known as the rigidity index, a key parameter in determining the type of behaviour observed in nanoindentation and nanoscratching wear [44-46]. The ratio $H / E$ can be regarded as a tool to describe, rank, or calculate values for performance criteria which are important in defining the wear resistance of a material, such as the elastic strain to failure, the critical yield pressure for plastic deformation, and the fracture toughness. A high $H / E$ ratio is often a reliable indicator of good wear resistance in a coating or layers $[45,47]$.

The pristine specimen shows a higher $H / E$ ratio when compared to that of the implanted samples (refer to Figure $7(\mathrm{c})$ ). This implies that $\mathrm{F}$ ion implantation of the $\mathrm{B}_{6} \mathrm{O}$ surface at a larger fluence is expected to cause a considerable increase in the surface plasticity. The experimental sliding wear test data is not available at present. However, using this rigidity index approximation, we suspect that the wear resistance from the ion-irradiated surfaces is expected to degrade at a larger fluences of implantation.

The intrinsic hardness clearly correlates very well with the $H / E$ ratio; this is no coincidence since hardness (or the plasticity) is known to have the decisive role of the surface layer on friction properties $[45,46]$.

A comparison of the $H / E$ ratio of hot-pressed $\mathrm{B}_{6} \mathrm{O}$ with other ultrahard ceramic materials is shown in Table 3.

3.2.4. Meyer's Index. To date, there exists immense experimental and theoretical evidence suggesting that, for some ceramic materials, the evaluated hardness value is not a material constant but rather a function of either the applied test load or the depth of the indentation - the indentation size effect (ISE) [48-52]. Several studies have reported that Meyer's law is sufficient to indicate the existence of ISE, although considered inadequate when describing the origins of ISE $[48,50]$. The classic power law relationship shown in (1) is commonly known as Meyer's law:

$$
P=A \cdot h^{n} .
$$

Both $A$ and $n$ are constants for a particular sample. The descriptive parameters are usually deduced by a suitable regression analysis of the experimental load-displacement relations for the loading segment.

The parameter $n$ is also known as the size-effect index. It is usually considered as a measure of ISE [50, 52]. The Meyer index has been experimentally observed to be between 1.5 and 2.0 for ceramics [48]. For the normal ISE behaviour, the exponent $n<2$ - the measured hardness apparently decreases with increasing applied test load. When $n>2$, there is the reverse ISE behaviour. When $n=2$, the hardness is independent of the applied test load.

In this study ISE curves were modelled on the basis of the Meyer's model [50,53]. Figure 7(d) shows an increase in $n$ with the increasing ion dose of fluorine ions. In other words, there is a point to make at higher doses where $n \rightarrow 2$; it appears there is the diminishing evidence of indentation size effects in hardness with increasing fluorine ion doses, and a single hardness value for the material exists.

\section{Conclusions}

The following conclusions are obtained from this study.

(i) For $\mathrm{F}^{+}$implantation at fluences below $5.0 \times 10^{15}$ ions $/ \mathrm{cm}^{2}$ the hot-pressed $\mathrm{B}_{6} \mathrm{O}$ samples resist amorphization and retain the $\mathrm{B}_{6} \mathrm{O}$ crystal structure. However, for fluences above $5.0 \times 10^{15} \mathrm{ions} / \mathrm{cm}^{2}$, the signature Raman spectrum of $\mathrm{B}_{6} \mathrm{O}$ disappears. Furthermore, beyond $5.0 \times 10^{15} \mathrm{ions} / \mathrm{cm}^{2}$, the Raman spectra appear to reveal that the fluorine implants in $\mathrm{B}_{6} \mathrm{O}$ matrix could influence the precipitation of ionbeam-synthesized clusters of a $\mathrm{B}_{x} \mathrm{O}_{y} \mathrm{~F}_{z}$ phase.

(ii) AFM and SEM images complement the Raman spectroscopy results on the existence of agglomerated ion-beam-synthesized clustered particles on the ionimplanted specimen surface. Although not conclusive, the EDX compositional analysis hints that the clustered particles have a $\mathrm{B}_{x} \mathrm{O}_{y} \mathrm{~F}_{z}$ stoichiometry. The exact structure and stoichiometry of the new phase are yet to be determined.

(iii) In general, fluorine implantation of the specimen leads to an overall decrease in the intrinsic hardness and the elastic modulus of the material. These trends reflect on the changes in the structure or the material, the mechanism of plastic deformation of the irradiated material, and most probably, ionimplantation-induced amorphization of the pristine structure.

(a) This relation tentatively supports the suggestion that plastic flow is the main deformation mechanism in ion-implanted hot-pressed ceramic $\mathrm{B}_{6} \mathrm{O}$ material. The softening of the ionimplanted specimen can be attributed to the amorphization of the surface layer, as identified by the micro-Raman spectroscopy characterization results. 
(iv) The decrease in both the $H / E$ ratio and the Meyer's index with ion dose might imply that $\mathrm{F}$ ion implantation of the $\mathrm{B}_{6} \mathrm{O}$ surface at a larger fluence is expected to cause a considerable increase in the surface plasticity.

\section{Appendices}

\section{A. Oliver and Pharr Analysis Approach}

The nanoindentation technique has been established as a powerful means of characterizing the near-surface mechanical properties of materials [54]. This technique relies on high-resolution instruments that simultaneously measure the load $P$ and indenter displacements $h$, during the loading and unloading indentation steps. The important parameters obtained from the resultant $P$ - $h$ curve, which are schematically illustrated in Figure 8 , are the peak load $P_{\max }$, the maximum penetration depth $h_{\max }$, final penetration depth $h_{f}$, and the contact stiffness $S$. The indentation analysis procedure developed by Oliver and Pharr (O\&P) has been widely used for hard materials such as metals and ceramics $[38,39,54]$.

The O\&P method makes use of the data taken from the upper portion of the unloading curve fitted with the powerlaw relation given as

$$
P=\alpha \cdot\left(h-h_{f}\right)^{m}
$$

where $m$, the displacement exponent in the loaddisplacement relation and $a$, an unloading fitting parameter dependent on the elastic response of the material, are empirical constants to be determined using the power fitting of unloading data [49].

The derivative of $P$ (A1) with respect to $h$ yields the contact stiffness $S$, which is the initial unloading slope of the $P$ - $h$ curve:

$$
\begin{aligned}
S & =\left(\frac{d P}{d h}\right)_{\text {unloading }} \\
& =m \cdot \alpha \cdot\left(h-h_{f}\right)^{m-1}
\end{aligned}
$$

The contact depth of the indent impression $h_{c}$ can either be derived by extrapolating the initial slope of the unloading $P$ - $h$ curve down to $P=0$ or otherwise determined using an empirical formula as observed by Oliver and Pharr [38, 39] given by

$$
h_{c}=h_{\max }-\epsilon \cdot \frac{P_{\max }}{S}
$$

where, in this case for the Berkovich indenter geometry, $\epsilon=$ 0.75 [38].

The contact area $A_{c}$ is the cross-sectional area at $h_{c}[55$, 56]. Various experimental [56] and numerical [57] studies have established that, for the Berkovich indenter geometry,

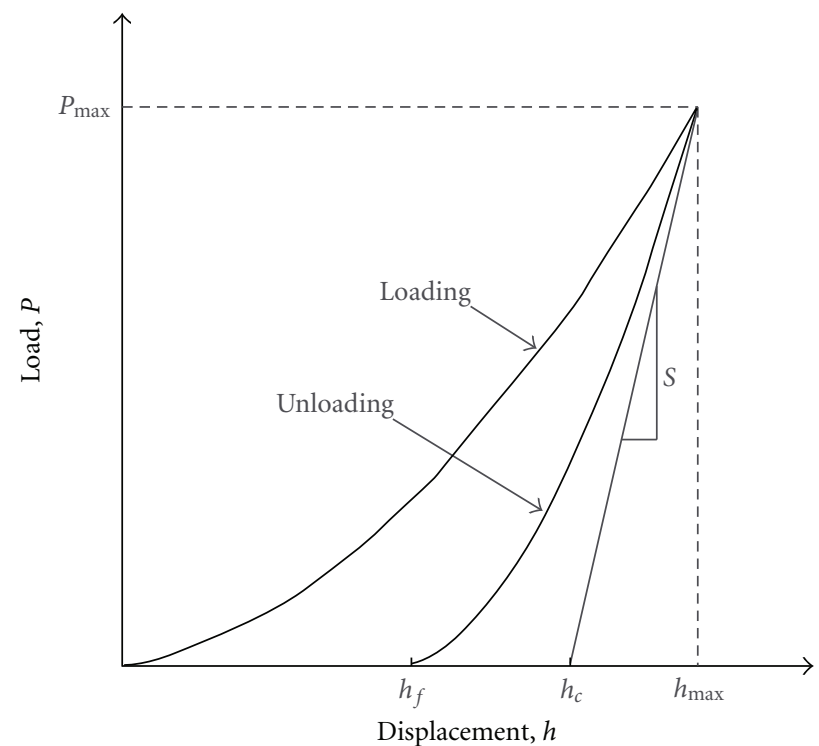

Figure 8: A typical load-displacement curve during a loadingunloading cycle where $h_{\max }$ is the maximum indenter displacement at peak indentation load $P_{\max }, S$ is the initial unloading slope of the load-displacement curve, and $h_{c}$ is the contact depth.

the projected $A_{c}$ can be approximated by the empirical formula:

$$
\begin{aligned}
A_{c}\left(h_{c}\right)=( & 24.56 \cdot h_{c}^{2}+C_{1} \cdot h_{c}^{1 / 2}+C_{2} \cdot h_{c}^{1 / 4} \\
& \left.+C_{3} \cdot h_{c}^{1 / 8}+\cdots+C_{8} \cdot h_{c}^{1 / 125}\right),
\end{aligned}
$$

where $C_{1}, C_{2}, \ldots, C_{8}$ are constants determined by curvefitting procedures $[55,56]$ and are all defined based on the indenter tip radius [49]. However, for the Berkovich indenter geometry, projected area can be reduced to $A_{c}\left(h_{c}\right) \approx$ $24.56 \cdot h_{c}^{2}$ without compromising the accuracy of the results $[54,55,58]$.

When $S$ and $A_{c}$ have been determined, the specimen's elastic modulus $E_{s}$ or simply $E$ can then be evaluated using

$$
\frac{1}{E_{r}}=\frac{1-v_{s}^{2}}{\mathbf{E}_{\mathbf{s}}}+\frac{1-v_{i}^{2}}{E_{i}},
$$

where $v_{s}$ and $v_{i}$ are, respectively, the specimen and indenter Poisson ratios, $E_{i}$ is the indenter elastic modulus $[54,58]$, and $E_{r}$ is the reduced elastic modulus given by

$$
E_{r}=\frac{\sqrt{\pi}}{2 \beta} \cdot \frac{S}{\sqrt{A_{c}}}
$$

where $\beta$ is a correctional factor introduced by King [59] to address the lack of indenter symmetry; for the Berkovich indenter $\beta=1.034$ [58].

The indentation hardness $H$ has long been defined as the test force $P$ divided by the projected area of contact $A_{c}[60]$ :

$$
H=\frac{P_{\max }}{A_{c}} .
$$




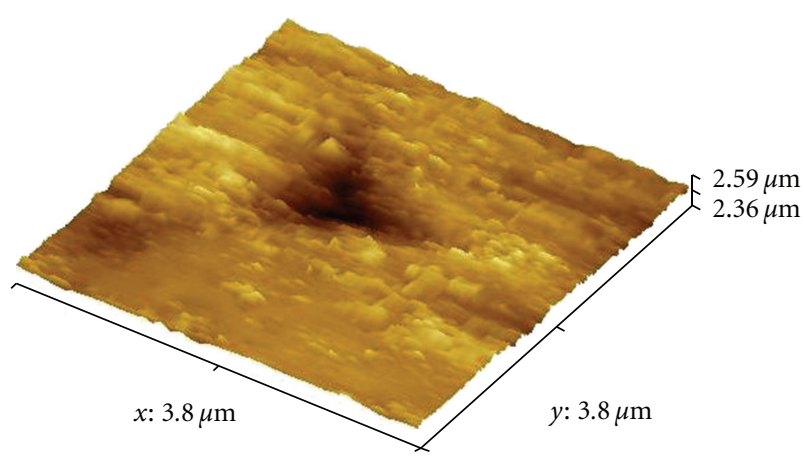

(a) Specimen $\mathrm{A}$

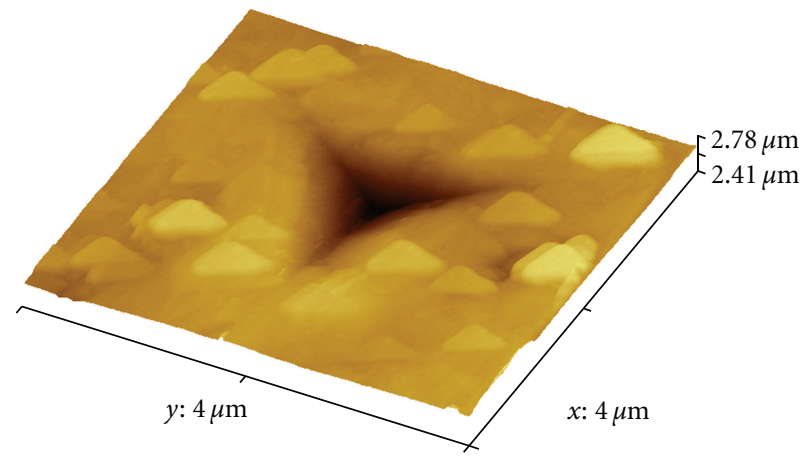

(c) Specimen D

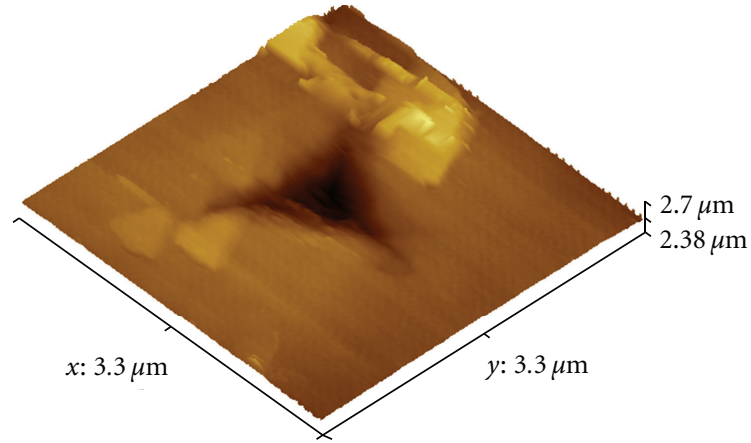

(b) Specimen C

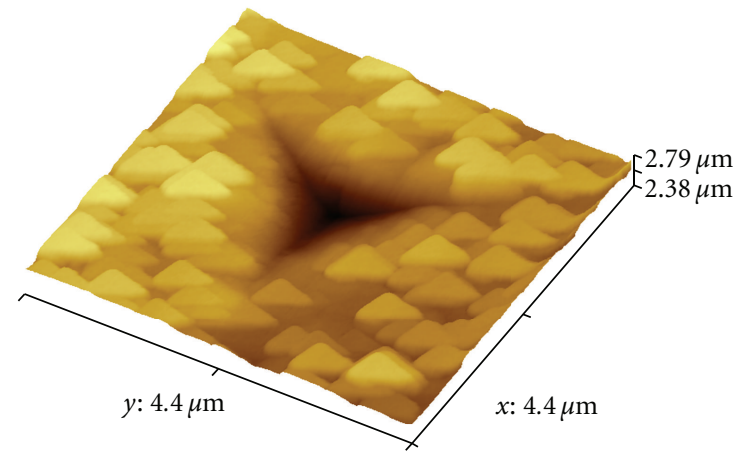

(d) Specimen G

FIGURE 9: AFM images showing what could possibly be clusters of nanoparticles embedded in the samples synthesized by fluorine-ion-beam implantation, (a) unimplanted specimen A, and ((b)-(d)) fluorine-implanted specimens C, D, and G.

However, it is also generally understood that hardness values derived using (A7) are often depth and load dependent; a single value is often inadequate to implicitly characterize the material property.

In order to extract the true or the intrinsic hardness of the specimen we applied an important material characteristic ratio, $P / S^{2}$, first proposed by Joslin and Oliver $[61,62]$, expressed as

$$
\frac{P}{S^{2}}=\frac{\pi}{4 \beta^{2}} \cdot \frac{\mathbf{H}(\mathbf{E})}{E_{r}^{2}} .
$$

Evidently, $P / S^{2}$ is independent of $h$ and $A_{c}$ [62]. Therefore, if $P$ is known and $S$ and $E_{r}$ have been predetermined, the intrinsic harness of specimen, $H(E)$, can be evaluated using (A8).

In summary, the method outlined here has been applied in this study to extract the material nanomechanical properties ( $E$ from (A5) and $H(E)$ from (A8) [62]) from the measured nanoindentation data.

\section{B. Supplementary Results: AFM Analysis}

The AFM image of the pristine $\mathrm{B}_{6} \mathrm{O}$ specimen surface is shown in Figure 9(a). Using Gwyddion v2.24 for profilometric data analysis, the surface roughness of the specimen was determined from the AFM images. The specimen surface appears to be characterized with an average roughness $\left(R_{a}\right)$ of about $7 \mathrm{~nm}$ with a root mean square surface roughness amplitude $\left(R_{q}\right)$ of $9 \mathrm{~nm}$.

The AFM images all bear Berkovich indenter impressions from hardness testing because the imaging was originally intended to give an intuitive understanding of the state of the specimen surfaces after nanoindentation. However, as shown in Figures 9(b)-9(d), striking morphological and structural transformations of the pristine material under ion irradiation have been observed.

The AFM images taken on the implanted samples depict an entirely different surface character from the pristine. Firstly, the images show compelling visual evidence of ionbeam-synthesized nanocrystalline structures decorating the specimen surfaces. Similar AFM structures have been also observed in metal ion-implanted oxide insulators by several authors and are usually attributed to the formation of the nanoparticles. Secondly, detailed image analysis measurements have demonstrated that the height of the particles is in the order of a few nanometres, with the average horizontal size of about $60 \mathrm{~nm}$. However, it should be pointed out (at this stage) that, by using AFM observations, lateral dimensions of nanoclusters are usually enlarged due to the tip-object convolution effect and only height measurements can provide the real size of the main-size objects. Thirdly, we have also attributed the ion-beamsynthesized nanocrystalline structures observed in Figures 9(b) -9 (d) to explain the variations of the line shapes of the Raman spectra of $\mathrm{F}$ ion-implanted hot-pressed $\mathrm{B}_{6} \mathrm{O}$ as 
shown in Figure 3 and reference [14]. Fourthly and lastly, the surfaces of the implanted samples appear to be much smoother in appearance than those of the pristine sample [63], tentatively suggestive that possible sputtering and other dynamic processes could have influenced the surface morphology of the specimen during implantation.

\section{Acknowledgments}

The authors are appreciative for the valuable contributions of O. T. Johnson, M. Herrmann, W. Goosen, J. Neethling, the Nelson Mandela Metropolitan University, and the Centre for Scientific and Industrial Research's National Centre for Nanostructured Materials. The financial support from the DST/NRF Centre of Excellence in Strong Materials and University of the Witwatersrand Mellon Postgraduate Award is also gratefully acknowledged.

\section{References}

[1] K. J. Kirkby and R. P. Webb, "Ion Implanted Nanostructures," in Encyclopedia of Nanoscience and Nanotechnology, H. S. Nalwa, Ed., vol. 4, pp. 1-11, American Scientific Publishers, 2004.

[2] I. Jain and G. Agarwal, "Ion beam induced surface and interface engineering," Surface Science Reports, vol. 66, no. 3-4, pp. 77-172, 2011.

[3] A. L. Stepanov, "Synthesis of silver nanoparticles in dielectric matrix by ion implantation: a review," Reviews on Advanced Materials Science, vol. 26, no. 1-2, pp. 1-29, 2010.

[4] J. F. Prins, "Modification, doping and devices in implanted diamond," in Properties of Natuaral and Synthetic Diamong, chapter 8, pp. 301-341, Academic Press Limited, 1992.

[5] J. Ghatak, B. Satpati, M. Umananda et al., "Characterization of ion beam induced nanostructures," Nuclear Instruments and Methods in Physics Research B, vol. 244, no. 1, pp. 45-51, 2006.

[6] D. K. Avasthi and J. C. Pivin, "Ion beam for synthesis and modification of nanostructures," Current Science, vol. 98, no. 6, pp. 780-792, 2010.

[7] H. Hosono and H. Kawazoe, "Approach to novel crystalline and amorphous oxide materials for optoelectronics by ion implantation," Materials Science and Engineering B, vol. 41, no. 1, pp. 39-45, 1996.

[8] Y. Shen, X. Li, Z. Wang et al., "Fabrication and thermal evolution of nanoparticles in $\mathrm{SiO}_{2}$ by $\mathrm{Zn}$ ion implantation," Journal of Crystal Growth, vol. 311, no. 21, pp. 4605-4609, 2009.

[9] R. MacHaka, R. M. Erasmus, and T. E. Derry, "Formation of cBN nanocrystals by $\mathrm{He}^{+}$implantation into hBN," Diamond and Related Materials, vol. 19, no. 10, pp. 1131-1134, 2010.

[10] I. D. Desnica-Frankovi, K. Furi, U. V. Desnica, M. C. Ridgway, and C. J. Glover, "Structural modifications in amorphous Ge produced by ion implantation," Nuclear Instruments and Methods in Physics Research B, vol. 178, no. 1-4, pp. 192-195, 2001.

[11] T. W. H. Oates, L. Ryves, F. A. Burgmann et al., "Ion implantation induced phase transformation in carbon and boron nitride thin films," Diamond and Related Materials, vol. 14, no. 8, pp. 1395-1401, 2005.

[12] F. Komarov, L. Vlasukova, W. Wesch et al., "Formation of InAs nanocrystals in Si by high-fluence ion implantation," Nuclear
Instruments and Methods in Physics Research B, vol. 266, no. 16 , pp. 3557-3564, 2008.

[13] J. I. Oñate, F. Alonso, and A. García, "Improvement of tribological properties by ion implantation," Thin Solid Films, vol. 317, no. 1-2, pp. 471-476, 1998.

[14] R. Machaka, T. E. Derry, and I. Sigalas, "Nanoindentation hardness of hot-pressed boron suboxide," Materials Science and Engineering A, vol. 528, no. 18, pp. 5778-5783, 2011.

[15] M. Herrmann, H. J. Kleebe, J. Raethel et al., "Field-assisted densification of superhard $\mathrm{B}_{6} \mathrm{O}$ materials with $\mathrm{Y}_{2} \mathrm{O}_{3} / \mathrm{Al}_{2} \mathrm{O}_{3}$ addition," Journal of the American Ceramic Society, vol. 92, no. 10, pp. 2368-2372, 2009.

[16] M. Herrmann, J. Raethel, A. Bales, K. Sempf, I. Sigalas, and M. Hoehn, "Liquid phase assisted densification of superhard $\mathrm{B}_{6} \mathrm{O}$ materials," Journal of the European Ceramic Society, vol. 29, no. 12, pp. 2611-2617, 2009.

[17] O. T. Johnson, I. Sigalas, E. N. Ogunmuyiwa, H. J. Kleebe, M. M. Müller, and M. Herrmann, "Boron suboxide materials with Co sintering additives," Ceramics International, vol. 36, no. 6, pp. 1767-1771, 2010.

[18] A. Andrews, M. Herrmann, T. C. Shabalala, and I. Sigalas, "Liquid phase assisted hot pressing of boron suboxidematerials," Journal of the European Ceramic Society, vol. 28, no. 8, pp. 1613-1621, 2008.

[19] A. Andrews, Development of boron suboxide composites with improved toughness, Ph.D. thesis, School of Chemical and Metallurgical Engineering, University of the Witwatersrand0, 2009.

[20] C. S. Freemantle, The wear studies of boron suboxide based cutting tool materials in machining applications, M.S. thesis, School of Chemical and Metallurgical Engineering, University of the Witwatersrand, 2010.

[21] R. Machaka, B. W. Mwakikunga, E. Manikandan, T. E. Derry, and I. Sigalas, "Raman spectrum of hot-pressed boron suboxide," Advanced Materials Letters, vol. 2, p. 68, 2011.

[22] J. Lowther, Personal Communication, 2009.

[23] J. F. Prins, "Ion-implanted structures and doped layers in diamond," Materials Science Reports, vol. 7, no. 7-8, pp. 271364, 1992.

[24] J. Ziegler, SRIM2010 (Software package), 2010, http://www .srim.org/.

[25] P. Klapetek, D. Necas, and C. Anderson, Gwyddion v2.24 (Software package), 2010, http://gwyddion.net/.

[26] R. Machaka, B. W. Mwakikunga, E. Manikandan, T. E. Derry, and I. Sigalas, "Structural transformation in ultrahard $\mathrm{B}_{6} \mathrm{O}$ induced by F-ion implantation studied by micro-Raman spectroscopy," Unpublished.

[27] O. T. Johnson, Improvement on the mechanical properties of boron suboxide $\left(B_{6} 0\right)$ based composites using other compounds as second phase, M.S. thesis, School of Chemical and Metallurgical Engineering, University of the Witwatersrand, 2009.

[28] O. T. Johnson, I. Sigalas, and M. Herrmann, "Microstructure and interfacial reactions between $\mathrm{B}_{6} \mathrm{O}$ and ( $\mathrm{Ni}, \mathrm{Co}$ ) couples," Ceramics International, vol. 36, no. 8, pp. 2401-2406, 2010.

[29] Z. Wang, Y. Zhao, P. Lazor, H. Annersten, and S. K. Saxena, "In situ pressure Raman spectroscopy and mechanical stability of superhard boron suboxide," Applied Physics Letters, vol. 86, no. 4, Article ID 041911, pp. 1-41911, 2005.

[30] H. Werheit and U. Kuhlmann, "FTIR and FT Raman spectra of $\mathrm{B}_{6} \mathrm{O}$," Journal of Solid State Chemistry, vol. 133, no. 1, pp. 260-263, 1997. 
[31] S. Yu, Y. Ji, T. Li et al., "Nanofilms with clusters of boron suboxide and their infrared absorption," Solid State Communications, vol. 115, no. 6, pp. 307-311, 2000.

[32] V. L. Solozhenko, O. O. Kurakevych, and P. Bouvier, "First and second-order Raman scattering of $\mathrm{B}_{6} \mathrm{O}$," Journal of Raman Spectroscopy, vol. 40, no. 8, pp. 1078-1081, 2009.

[33] C. S. R. Rao, S. Sundaram, R. L. Schmidt, and J. Comas, "Study of ion-implantation damage in GaAs:Be and InP:Be using Raman scattering," Journal of Applied Physics, vol. 54, no. 4, pp. $1808-1815,1983$.

[34] S. S. Kumar, M. A. Khadar, S. K. Dhara, T. R. Ravindran, and K. G. M. Nair, "Photoluminescence and Raman studies of ZnS nanoparticles implanted with $\mathrm{Cu}^{+}$ions," Nuclear Instruments and Methods in Physics Research B, vol. 251, no. 2, pp. 435-440, 2006.

[35] A. K. Arora, M. Rajalakshmi, T. R. Ravindran, and V. Sivasubramanian, "Raman spectroscopy of optical phonon confinement in nanostructured materials," Journal of Raman Spectroscopy, vol. 38, no. 6, pp. 604-617, 2007.

[36] M. Nastasi and J. W. Mayer, Ion Implantation and Synthesis of Materials, Springer, Berlin, Germany, 2006.

[37] W. C. Oliver and G. M. Pharr, "Improved technique for determining hardness and elastic modulus using load and displacement sensing indentation experiments," Journal of Materials Research, vol. 7, no. 6, pp. 1564-1580, 1992.

[38] W. C. Oliver and G. M. Pharr, "Measurement of hardness and elastic modulus by instrumented indentation: advances in understanding and refinements to methodology," Journal of Materials Research, vol. 19, no. 1, pp. 3-20, 2004.

[39] G. M. Pharr and A. Bolshakov, "Understanding nanoindentation unloading curves," Journal of Materials Research, vol. 17, no. 10, pp. 2660-2671, 2002.

[40] X. Jiao, H. Jin, F. Liu et al., "Synthesis of boron suboxide $\left(\mathrm{B}_{6} \mathrm{O}\right)$ with ball milled boron oxide $\left(\mathrm{B}_{2} \mathrm{O}_{3}\right)$ under lower pressure and temperature," Journal of Solid State Chemistry, vol. 183, no. 7, pp. 1697-1703, 2010.

[41] S. R. Jian, G. J. Chen, and J. Y. Juang, "Nanoindentationinduced phase transformation in ( $\left.\begin{array}{lll}1 & 1 & 0\end{array}\right)$-oriented Si singlecrystals," Current Opinion in Solid State and Materials Science, vol. 14, no. 3-4, pp. 69-74, 2010.

[42] C. A. Schuh, "Nanoindentation studies of materials," Materials Today, vol. 9, no. 5, pp. 32-40, 2006.

[43] J. G. Wang, B. W. Choi, T. G. Nieh, and C. T. Liu, "Crystallization and nanoindentation behavior of a bulk $\mathrm{Zr}$ Al-Ti-Cu-Ni amorphous alloy," Journal of Materials Research, vol. 15, no. 3, pp. 798-807, 2000.

[44] N. Laidania, A. Miotello, and J. Perrière, "Chemical, mechanical and electrical properties of $\mathrm{CN}_{\mathrm{x}}$-films produced by reactive sputtering and $\mathrm{N}^{+}$-implantation in carbon films," Applied Surface Science, vol. 99, no. 4, pp. 273-284, 1996.

[45] A. Leyland and A. Matthews, "On the significance of the H/E ratio in wear control: a nanocomposite coating approach to optimised tribological behaviour," Wear, vol. 246, no. 1-2, pp. $1-11,2000$.

[46] P. Lemoine, J. P. Quinn, P. Maguire, and J. A. McLaughlin, "Comparing hardness and wear data for tetrahedral amorphous carbon and hydrogenated amorphous carbon thin films," Wear, vol. 257, no. 5-6, pp. 509-522, 2004.

[47] T. Oberle, "Properties influencing the wear of metals," Journal of Metrologia, vol. 3, p. 438, 1951.

[48] J. Gong, J. Wu, and Z. Guan, "Analysis of the indentation size effect on the apparent hardness for ceramics," Materials Letters, vol. 38, no. 3, pp. 197-201, 1999.
[49] J. Gong, H. Miao, and Z. Peng, "A new function for the description of the nanoindentation unloading data," Scripta Materialia, vol. 49, no. 1, pp. 93-97, 2003.

[50] O. Şahin, O. Uzun, U. Kölemen, and N. Uçar, "Mechanical characterization for $\beta$-Sn single crystals using nanoindentation tests," Materials Characterization, vol. 59, no. 4, pp. 427434, 2008.

[51] O. Sahin, O. Uzun, M. Sopicka-Lizer, H. Gocmez, and U. Kölemen, "Dynamic hardness and elastic modulus calculation of porous SiAlON ceramics using depth-sensing indentation technique," Journal of the European Ceramic Society, vol. 28, no. 6, pp. 1235-1242, 2008.

[52] K. Sangwal, "On the reverse indentation size effect and microhardness measurement of solids," Materials Chemistry and Physics, vol. 63, no. 2, pp. 145-152, 2000.

[53] H. Li and R. C. Bradt, "The indentation load/size effect and the measurement of the hardness of vitreous silica," Journal of Non-Crystalline Solids, vol. 146, pp. 197-212, 1992.

[54] A. Fischer-Cripps, Nanoindentation, Springer, New York, NY, USA, 2nd edition, 2004.

[55] J. Gong, H. Miao, and Z. Peng, "Analysis of the nanoindentation data measured with a Berkovich indenter for brittle materials: effect of the residual contact stress," Acta Materialia, vol. 52, no. 3, pp. 785-793, 2004.

[56] J. Gong, H. Miao, and Z. Peng, "On the contact area for nanoindentation tests with Berkovich indenter: case study on soda-lime glass," Materials Letters, vol. 58, no. 7-8, pp. 13491353, 2004.

[57] K. D. Bouzakis and N. Michailidis, "Indenter surface area and hardness determination by means of a FEM-supported simulation of nanoindentation," Thin Solid Films, vol. 494, no. 1-2, pp. 155-160, 2006.

[58] N. Janakiraman and F. Aldinger, "Indentation analysis of elastic and plastic deformation of precursor-derived Si-C-N ceramics," Journal of the European Ceramic Society, vol. 30, no. 3, pp. 775-785, 2010.

[59] R. B. King, "Elastic analysis of some punch problems for a layered medium," International Journal of Solids and Structures, vol. 23, no. 12, pp. 1657-1664, 1987.

[60] B. Mott, Microindentation Hardness Testing, Butterworths, London, UK, 1956.

[61] D. L. Joslin and W. C. Oliver, "New method for analyzing data from continuos depth-sensing microindentation tests," Journal of Materials Research, vol. 5, no. 1, pp. 123-126, 1990.

[62] X. Y. Zhou, Z. D. Jiang, H. R. Wang, and Q. Zhu, "A method to extract the intrinsic mechanical properties of soft metallic thin films based on nanoindentation continuous stiffness measurement technique," Journal of Physics, vol. 48, no. 1, article 204, pp. 1096-1101, 2006.

[63] E. H. Lee, M. B. Lewis, P. J. Blau, and L. K. Mansur, "Improved surface properties of polymer materials by multiple ion beam treatment," Journal of Materials Research, vol. 6, no. 3, pp. 610$628,1991$. 

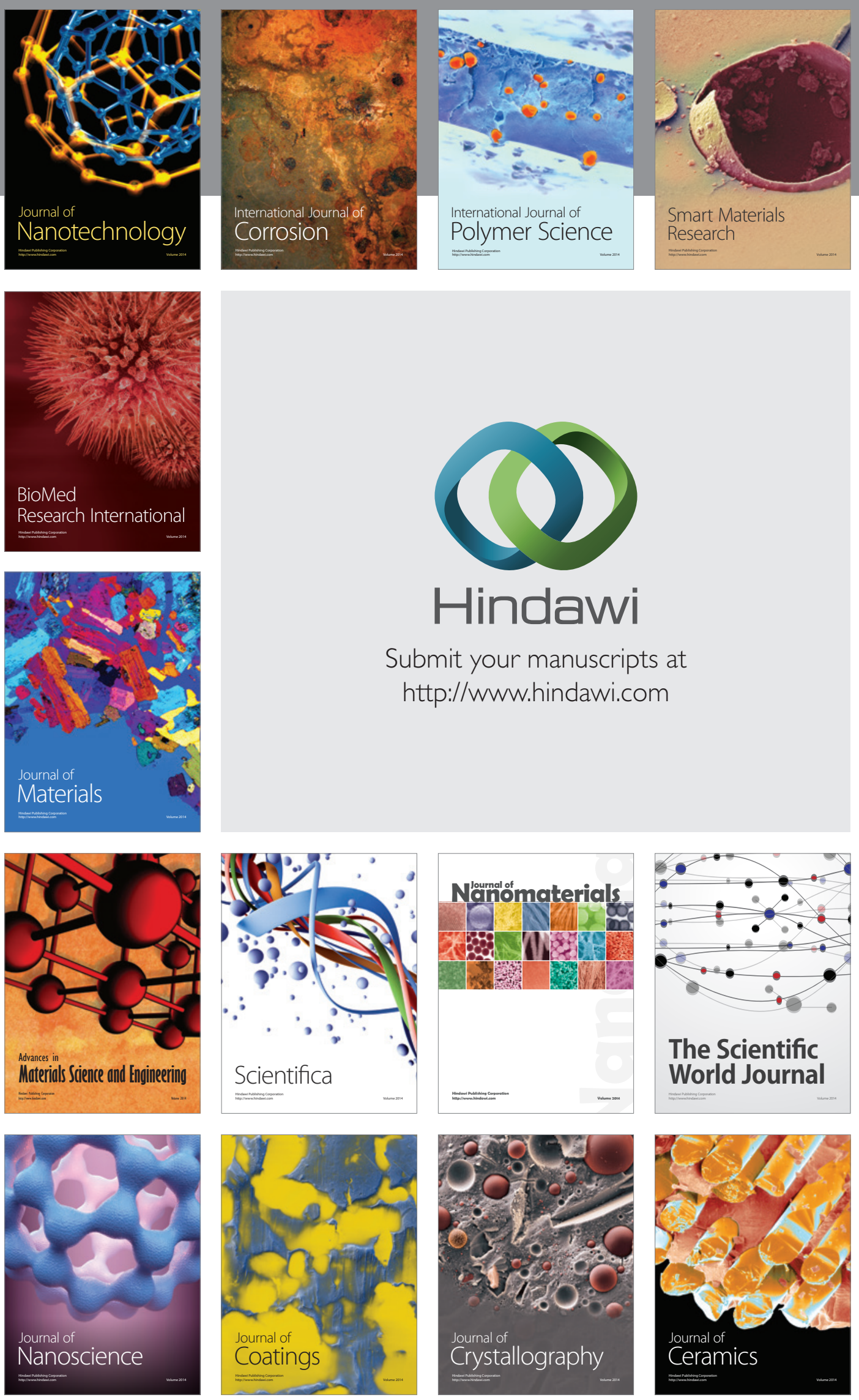

The Scientific World Journal

Submit your manuscripts at

http://www.hindawi.com

\section{World Journal}

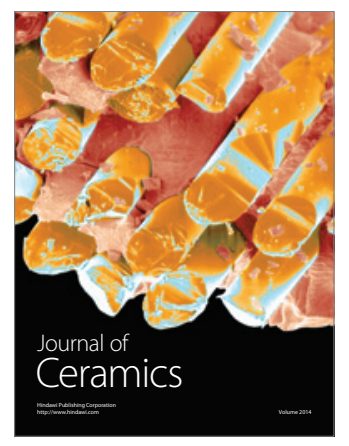

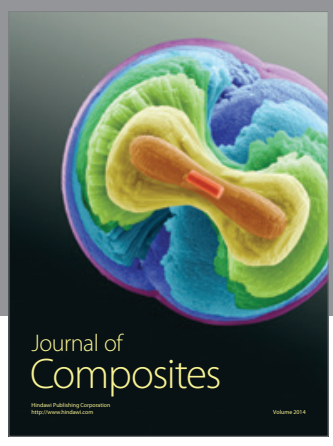
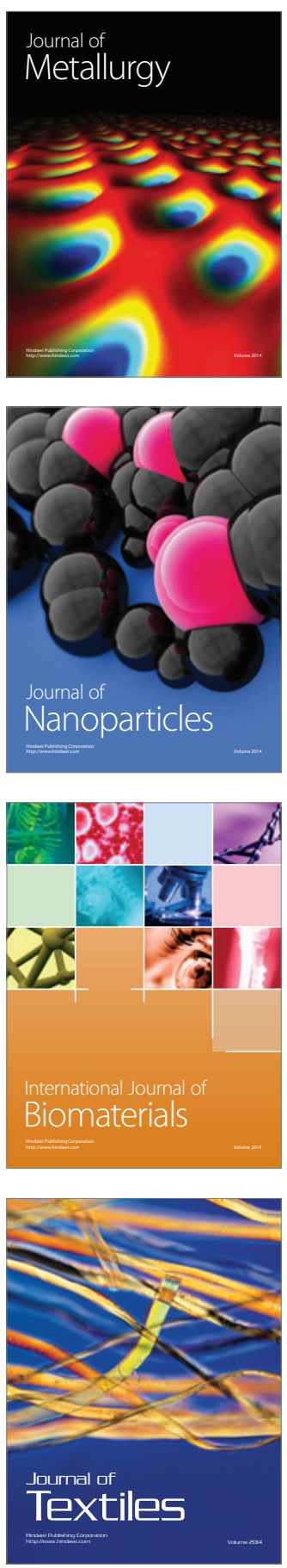